\title{
Klinik Hukum Peningkatan Partisipasi Masyarakat Dalam Penyusunan Rencana Zonasi Wilayah Pesisir dan Pulau-Pulau Kecil
}

\author{
Haris Retno Susmiyati*1, Rahmawati Al Hidayah² \\ 1,2Fakultas Hukum, Universitas Mulawarman \\ *e-mail: harisretno@fh.unmul.ac.id ${ }^{1}$, ,rahmawatialhidayah@gmail.com²
}

\begin{abstract}
Public participation in the preparation of regional regulations is a right guaranteed by the constitution, especially if the regulations to be made are closely related to the sustainability of the community's living space. This is what underlies community service activities carried out to the coastal communities of Balikpapan Bay through groups of fishermen and activists who focus on environmental and coastal issues with the aim of providing legal understanding and awareness to be involved or participate in the preparation of RZWP3K. With the FGD method through 3 stages which include presentation of material, identification of problems, and preparation of policy briefs, it is hoped that it will be able to provide concrete efforts for community participation in the preparation of regional regulations. Based on the results of community service activities, legal awareness was formed for the participants who attended, as evidenced by the involvement of all participants in the preparation of a policy brief that was submitted to the Kaltim DPRD - Special Committee on the Draft Regional Regulation. at RZWP3K East Kalimantan.
\end{abstract}

Keywords: participation, public, RZWP3K

\begin{abstract}
Abstrak
Partisipasi masyarakat dalam penyusunan peraturan daerah merupakan hak yang dijamin konstitusi, terlebih jika regulasi yang akan dibuat sangat berkaitan dengan keberlangsungan ruang hidup masyarakat. Hal inilah yang mendasari kegiatan pengabdian masyarakat dilakukan kepada masyarakat pesisir teluk Balikpapan melalui kelompok nelayan dan aktivis yang fokus pada isu lingkungan dan pesisir dengan tujuan untuk memberikan pemahaman dan kesadaran hukum untuk terlibat atau berpartisipasi dalam penyusunan RZWP3K. Dengan metode diskusi grup terarah melalui 3 tahapan antara lain pemaparan materi, identifikasi masalah, dan penyusunan policy brief diharapkan mampu memberikan upaya konkrit berpartisipasinya masyarakat dalam penyusunan peraturan daerah. Berdasarkan hasil kegiatan pengabdian telah terbentuk kesadaran hukum bagi peserta yang hadir dibuktikan dengan terlibatnya seluruh peserta dalam menyusun policy brief yang disampaikan kepada DPRD Kalimantan Timur - Pansus Rancangan Peraturan Daerah tentang RZWP3K Kalimantan Timur.
\end{abstract}

Kata kunci: partisipasi, masyarakat, RZWP3K

\section{PENDAHULUAN}

Rencana zonasi wilayah pesisir dan pulau-pulau kecil atau yang disingkat RZWP3K merupakan mandat Undang-Undang Nomor 27 Tahun 2007 jo. Undang-Undang Nomor 1 Tahun 2014 tentang perubahan atas Undang-Undang Nomor 27 Tahun 2007 tentang Pengelolaan wilayah pesisir dan pulau-pulau kecil. RZWP3K merupakan produk hukum yang sangat penting dalam memberikan arahan pemanfaatan ruang bagi optimalisasi pendayagunaan sumber daya pesisir dan pulau-pulau kecil secara ekonomi, juga memberikan kepastian ruang terhadap luasan kawasan konservasi laut.

Indonesia merupakan negara kepulauan terbesar di dunia, dengan 17.499 pulau dengan luas wilayah laut 3,25 juta km2 dan 2,55 juta km2 merupakan Zona Ekonomi Eksklusif (Pratama, 2020). Indonesia sebagai negara peserta penandatanganan Konvensi Keakenaragaman Hayati (United Nation Convention Biological Diversity) 1992, mempunyai kewajiban mengimplementasikan ketentuan tersebut dalam kebijakan nasional (Kementerian Kelautan dan Perikanan, 2016);(Kementerian Lingkungan Hidup, n.d.). Sebagai salah satu implementasi kewajiban terhadap kawasan konservasi, hingga tahun 2019, luas kawasan konservasi perairan di Indonesia tercatat telah mencapai 23,918 juta hektar, dengan jumlah kawasan sebanyak 201 kawasan (Julheri, 2020). 
Kewenangan penyusunan RZWP3K yang semula ada di kabupaten/kota bergeser ke provinsi berdasarkan Undang-Undang Nomor 23 Tahun 2014 tentang Pemerintahan Daerah. Provinsi Kalimantan Timur melalui Dinas Kelautan dan Perikanan sedang menyusun dokumen RZWP3K yang telah bergulir prosesnya sejak tahun 2018,(Pemprov Kaltim, 2018).

Penyusunan peraturan Daerah RZWP3K sudah semestinya mengakomodir masyarakat yang berada di sekitar wilayah pesisir, namun berdasarkan pengaduan dari masyarakat yang tergabung dalam Forum Peduli Teluk Balikpapan dan Forum Nelayan Balikpapan kepada Pusat Studi Hukum Sumber Daya Alam Fakultas Hukum Universitas Mulawarman, tentang adanya rencana Pemerintah untuk menyusun usulan Raperda RZWP3K Provinsi Kalimantan Timur, namun tanpa melibatkan masyarakat dalam penyusunannya (Arumanto, 2018). Serta berdasarkan Paparan Koalisi masyarakat Sipil Kalimantan Timur tentang proses penyusunan RZWP3K Provinsi Kalimantan Timur tidak dilakukan dengan melibatkan partisipasi masyarakat yang menimbulkan kekhawatiran ancaman bagi ruang wilayah nelayan di laut. (Azis, 2018);(Koalisi Masyarakat Sipil Untuk Keadilan Pesisir dan Pulau-Pulau kecil, 2020). Pembahasan RZWP3K Kaltim difasilitasi dengan pembentukan Pansus (Kaltim, 2019), Penyusunan RZWP3K Provinsi Kalimantan Timur hingga September 2020 masih dalam tahapan pembahasan kembali di DPRD Provinsi Kalimantan Timur.

Kegiatan pengabdian menyasar masyarakat pesisir teluk balikpapan yang tergabung dalam kelompok nelayan, juga aktivis lingkungan yang fokus pada kelestarian lingkungan di Kalimantan Timur, yang mempunyai perhatian terhadap penyusunan RZWP3K Provinsi Kalimantan Timur. Kegiatan pengabdian masyarakat dilaksanakan dalam bentuk Klinik Hukum. Klinik hukum merupakan program dari Pusat Studi Sumber Daya Alam Fakultas Hukum Universitas Mulawarman. Tujuan program untuk memberikan pemahaman hukum mengenai peran, hak dan kewajiban masyarakat pesisir dalam penyusunan RZWP3K Provinsi Kalimantan Timur, seluruh proses ini kemudian dituangkan dalam bentuk policy brief yang disusun bersama kelompok nelayan teluk balikpapan dan Koalisi Masyarakat Sipil Kalimantan Timur sebagai masukan dalam penyusunan Raperda RZWP3K Provinsi Kalimantan Timur.

Wilayah pesisir dan pulau-pulau kecil merupakan bagian dari sumber daya alam yang dianugerahkan Tuhan Yang Maha Esa dan merupakankekayaan yang dikuasai negara, yang diperuntukkan untuk kemakmuran rakyat. Wilayah Pesisir dan Pulau-pulau kecil perlu dikelola dengan memperhatikan aspirasi dan partisipasi masyarakat dan tata nilai bangsa (Kasworo, 2017). Potensi sumber daya wilayah dan sumberdaya alam yang dimiliki Indonesia menjadikan kawasan pesisir penting bagi masyarakat salah satunya untuk sumber ketahanan pangan (Ramses et al., 2018).

Rencana zonasi wilayah pesisir dan pulau-pulau kecil (RZWP3K) merupakan mandat Undang-Undang Nomor 27 Tahun 2007 jo. Undang-Undang Nomor 1 Tahun 2014 tentang perubahan atas Undang-Undnag Nomor 27 Tahun 2007 tentang Pengelolaan wilayah pesisir dan pulau-pulau kecil. Penyusunannya merupakan kewajiban Pemerintah Daerah. Selain itu berdasarkan Undang-Undang Nomor 23 Tahun 2014 Tentang Pemerintahan Daerah Pasal 14 menyebutkan bahwa penyelenggaraan urusan bidang kelautan dibagi antara pemerintah pusat dan daerah provinsi. Ketentuan dalam lampiran Y menyebutkan bahwa pengelolaan ruang laut sampai dengan 12 mil diluar minyak dan gas bumi serta penerbitan izin dan pemanfaatan ruang laut dibawah 12 mil diluar minyak dan gas bumi menjadi kewenangan pemerintah daerah provinsi. Ketentuan ini berimplikasi terhadap kewajiban pemerintah daerah provinsi menetapkan peraturan daerah tentang RZWP3K.

Berdasarkan hasil kajian KPK dan kesepakatan bersama dengan 20 kementerian, 7 lembaga dan 34 provinsi, untuk menuntaskan persoalan di sektor kelautan salah satunya penyusunan RZWP3K (BPSD Pesisir dan Laut Padang, 2019). Wilayah Pesisir dan laut menjadi wilayah penting bagi kehidupan masyarakat, oleh karena itu penyusunan raperda RZWP3K sudah seharusnya melibatkan partisipasi masyarakat secara penuh. Partisipasi adalah prinsip bahwa 
setiap orang memiliki hak untuk terlibat dalam pengambilan keputusan di setiap kegiatan penyelenggaraan pemerintah, (Prihatiningtyas, 2019).

Pengabdian masyarakat ini didasarkan pada hasil penelitian proses penyusunan perda partisipatif (Kurnia et al., 2016) telaah akademik, terhadap penyusunan Raperda RZWP3K Provinsi Kalimantan Timur oleh Pusat Studi Hukum Sumber Daya Alam (PSH-SDA) Fakultas Hukum Universitas Mulawarman, yang menunjukkan adanya kewajiban hukum bagi partisipasi masyarakat dalam penyusunan Raperda RZWP3K (Hidayah, 2018).

\section{METODE}

Kegiatan pengabdian dilakukan melalui diskusi kelompok terarah dengan tahapan yaitu: Tahap Pertama, memberikan sosialisasi hukum terkait partisipasi masyarakat dalam penyusunan peraturan daerah khususnya tentang rencana zonasi wilyah pesisir dan pulau-pulau kecil (RZWP3K); Tahap kedua, mengidentifikasi masalah dalam pengelolaan pesisir dan tantangan pengaturannya; Tahap ketiga, menyusun bersama policy brief yang berisi masukan terhadap rancangan peraturan daerah tentang rencana zonasi wilayah pesisir dan pulu-pulau kecil di Provinsi Kalimantan Timur.

\section{HASIL DAN PEMBAHASAN}

Sumber Daya Alam Pesisir dan Pulau-Pulau Kecil memiliki peran yang penting bagi pendapatan negara dan daerah, serta menjadi ruang hidup masyarakat. Posisi strategis tersebut menempatkan Rancangan Penyusunan RZWP3K, menjadi sangat penting tidak hanya bagi pemerintah, namun juga bagi masyarakat yang kehidupan kesehariannya sangat bergantung pada kawasan pesisir dan pulau-pulau kecil. Sejak dimulainya penyusunan RZWP3K Provinsi Kalimantan Timur mendapatkan berbagai kritik dari masyarakat karena partisipasi masyarakat dalam penyusunan yang dilakukan pemerintah tidak dilakukan secara cukup.

Klinik Hukum partisipasi masyarakat dalam penyusunan RZWP3K telah dilaksanakan sesuai dengan tahapan yang direncanakan yakni Tahap Pertama, memberikan sosialisasi hukum terkait partisipasi masyarakat dalam penyusunan peraturan daerah; Tahap kedua, bersama-sama mengidentifikasi masalah yang dihadapi dalam pengelolaan pesisir dan tantangan pengaturannya; Tahap ketiga, menyusun bersama policy brief yang berisi masukan terhadap rancangan peraturan daerah tentang rencana zonasi wilayah pesisir dan pulau-pulau kecil di Provinsi Kalimantan Timur.

Tahap Pertama, Klinik hukum peningkatan partisipasi masyarakat dalam penyusunan RZWP3K, memberikan pemahaman hukum terkait partisipasi masyarakat dalam penyusunan peraturan daerah khususnya tentang rencana zonasi wilyah pesisir dan pulau-pulu kecil (RZWP3K); diikuti oleh 21 Peserta terdiri dari masyarakat pesisir teluk balikpapan yang tergabung dalam kelompok nelayan dan aktivis atau pegiat organisasi masyarakat sipil yang terkait dengan isu lingkungan dan pesisir. Tim pengabdian memulai klinik hukum dengan pemaparan mengenai hak konstitusi masyarakat untuk berpartisipasi dalam penyusunan peraturan daerah termasuk dalam penyusunan RZWP3K.

Tabel 1. Peserta Klinik Hukum

\begin{tabular}{clc}
\hline No & \multicolumn{1}{c}{ Lembaga dan Perorangan } & Jumlah (orang) \\
\hline 1. & Warga Balikpapan & 2 \\
2. & Forum Peduli Teluk Balikpapan & 2 \\
3. & Nelayan Pesisir Balipapan & 5 \\
4. & Jaringan Advokasi Lingkungan & 1 \\
5. & Jatam Kaltim & 2 \\
6. & Jatam Nasional & 1 \\
7. & Tim Kerja Perempuan dan Tambang (TKPT) & 1 \\
8. & Prakarsa Borneo & 1 \\
\hline
\end{tabular}




\begin{tabular}{lll}
\hline 9. & Mahasiswa & 4 \\
10. & Aliansi Masyarakat Adat Nusantara (AMAN) & 2 \\
& Kaltim & \\
& Jumlah & 21 \\
\hline
\end{tabular}

Bahwa RZWP3K akan memberikan kepastian hukum terhadap lokasi yang boleh dimanfaatkan untuk kepentingan ekonomi dan lokasi yang masuk kriteria konservasi sehingga tidak boleh ada kegiatan di lokasi tersebut. Untuk itu informasi mengenai peta zonasi yang didalamnya menyebutkan luasan tertentu harus diketahui oleh masyarakat secara terbuka karena hal tersebut merupakan hak masyarakat dalam proses penyusunan RZWP3K.

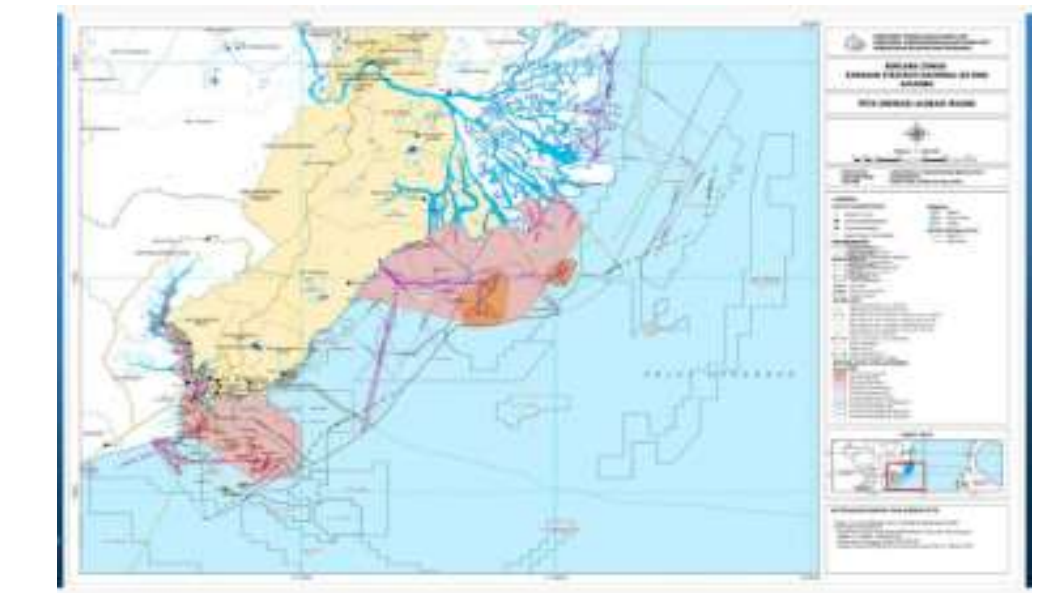

Gambar 1. Peta Wilayah Pesisir dan Pulau-Pulau Kecil di Kalimantan Timur Sumber : Dokumen Pansus RZWP3K Kaltim (2019)

Tahap Kedua, dilakukan setelah sesi pemaparan mengenai hak partisipasi masyarakat dalam penyusunan RZWP3K dilanjutkan sesi kedua yaitu mengidentifikasi masalah yang dialami langsung oleh masyarakat pesisir teluk balikpapan. Berikut gambaran hasil identifikasi masalah dalam kegiatan klinik hukum.

Tabel 2. Pemahaman terhadap Masalah Partisipasi Masyarakat Pesisir dalam Penyusunan RZWP3K

\begin{tabular}{|c|c|}
\hline Asal & Identifikasi Masalah \\
\hline JAL (Jaringan & 1. Perlu identifikasi wilayah mangrove dan ekosistemnya. \\
\hline Advokasi & 2. Teluk Balikpapan diusulkan menjadi wilayah konservasi \\
\hline Lingkungan )Kali & 3. Faktanya wilayah teluk balikpapan ada dibebani izin pelabuhan \\
\hline mantan Timur & $\begin{array}{l}\text { 4. Wilayah tangkap nelayan perlu diperhatikan mengingat } \\
\text { posisinya diapit oleh wilayah reklamasi dan wilayah migas }\end{array}$ \\
\hline $\begin{array}{l}\text { Forum Nelayan } \\
\text { Teluk }\end{array}$ & $\begin{array}{l}\text { 1. Mengusulkan agar teluk balikapan dapat menjadi Konservasi } \\
\text { laut daerah }\end{array}$ \\
\hline \multirow[t]{2}{*}{ Balikpapan } & $\begin{array}{l}\text { 2. Faktanya aktivitas nelayan diatas } 10 \text { mil masih mengalami } \\
\text { konflik dengan wilayah pengankutan batubara }\end{array}$ \\
\hline & $\begin{array}{l}\text { 3. Reklamasi di wilayah pesisir teluk balikpapan hanya akan } \\
\text { merugikan masyarakat pesisir. }\end{array}$ \\
\hline $\begin{array}{l}\text { JATAM (Jaringan } \\
\text { Advokasi }\end{array}$ & $\begin{array}{l}\text { 1. Rancangan Peta tematik RZWP3K tidak mengatur kawasan } \\
\text { tangkap nelayan. }\end{array}$ \\
\hline $\begin{array}{l}\text { Tambang) } \\
\text { Kaltim }\end{array}$ & $\begin{array}{l}\text { 2. Dalam draft hanya menyebutkan kawasan reklamasi, konsesi } \\
\text { tambang pasir dan pelabuhan }\end{array}$ \\
\hline
\end{tabular}




\begin{tabular}{|c|c|}
\hline $\begin{array}{l}\text { AMAN (Aliansi } \\
\text { Masyarakat Adat }\end{array}$ & $\begin{array}{l}\text { 1. Untuk masyarakat adat yang berada di wilayah pesisir baru } \\
\text { mulai mencoba untuk terlibat dalam isu pesisir dan karst }\end{array}$ \\
\hline Nusantara) & Selama ini masih focus pendampingan terkait wilayah darat, \\
\hline Kaltim & $\begin{array}{l}\text { hutan, kebun tanah masyarakat adat yang berkonflik dengan } \\
\text { perkebunan dan pertambangan }\end{array}$ \\
\hline $\begin{array}{l}\text { TKPT (Tim Kerja } \\
\text { Perempuan dan }\end{array}$ & $\begin{array}{l}\text { 1. Belum ada dokumen kajian lingkungan hidup strategis } \\
\text { (KLHS) }\end{array}$ \\
\hline Tambang) & 2. Perlu melakukan verifikasi prosedur penyusunan draft \\
\hline Kaltim & $\begin{array}{l}\text { RZWP3K, untuk memastikan apakah ada cacat prosedural } \\
\text { didalam proses penyusunannya. }\end{array}$ \\
\hline
\end{tabular}

Berdasarkan hasil identifikasi masalah bersama peserta, diperoleh informasi permasalahan dalam penyusunan RZWP3K dikelompokkan dalam 2 aspek yaitu aspek Formil dan aspek materiil. Aspek formil terkait prosedur yang dilakukan pemerintah dalam menyusun RZWP3K di bandingkan dengan ketentuan hukum yang seharusnya. Aspek Materiil adalah substansi atau isi pengaturan yang ada dalam Rancangan Perda RZWP3K.

Tabel 3. Klasifikasi Masalah dalam Penyusunan RZWP3K Kaltim

\begin{tabular}{|c|c|}
\hline Aspek Formil & Aspek Materil \\
\hline $\begin{array}{l}\text { 1. Mencermati Prosedur } \\
\text { penyusunan dokumen RZWP3K } \\
\text { Kalimantan Timur apakah sudah } \\
\text { sesuai dengan tahap-tahap } \\
\text { penyusunan sebagaimana yang } \\
\text { dituuangkan dalam pedoman } \\
\text { penyusunan RZWP3K. }\end{array}$ & $\begin{array}{l}\text { 1. Fakta kondisi wilayah teluk balikpapan } \\
\text { yang disekitarnya ada kegiatan } \\
\text { pertambangan migas, reklamasi dan } \\
\text { pelabuhan, menyempitkan ruang } \\
\text { nelayan sebagai masyarakat pesisir. } \\
\text { 2. } \begin{array}{l}\text { Mengusulkan wilayah teluk balikpapan } \\
\text { menjadi wilayah konservasi }\end{array}\end{array}$ \\
\hline $\begin{array}{l}\text { 2. Mencermati penyusunan } \\
\text { dokumen RZWP3K Kalimantan } \\
\text { Timur apakah sudah melibatkan } \\
\text { partisipasi masyarakat. }\end{array}$ & $\begin{array}{l}\text { 3. Draft dokumen RZWP3K tidak } \\
\text { menyebutkan/mengatur mengenai } \\
\text { wilayah tangkap nelayan. }\end{array}$ \\
\hline
\end{tabular}

Dalam tahap identifikasi masalah ini Tim Klinik Hukum mengarahkan bahwa kajian dokumen RZWP3K sangat luas sehingga harus ada skala prioritas dalam mengidentifikasi isu yang akan dijadikan masukan dalam penyusunan RZWP3K. dalam prosesnya disepakati bahwa kegiatan pengabdian klinik hukum ini akan melakukan analisa dokumen RZWP3K, berdasarkan data yang telah dimiliki masyarakat. Semua data perlu didokumentasikan agar dapat dicocokan atau disesuaikan dengan fakta dan dokumen lainnya. Berdasarkan ketersediaan data yang ada maka dilakukan evaluasi kesesuaian, Keselarasan dan Keseimbangan wilayah pesisir untuk dijadikan bahan penyusunan policy brief atau kertas kebijakan untuk disampaikan kepada pihak yang mengambil kebijakan baik legislative maupun eksekutif.
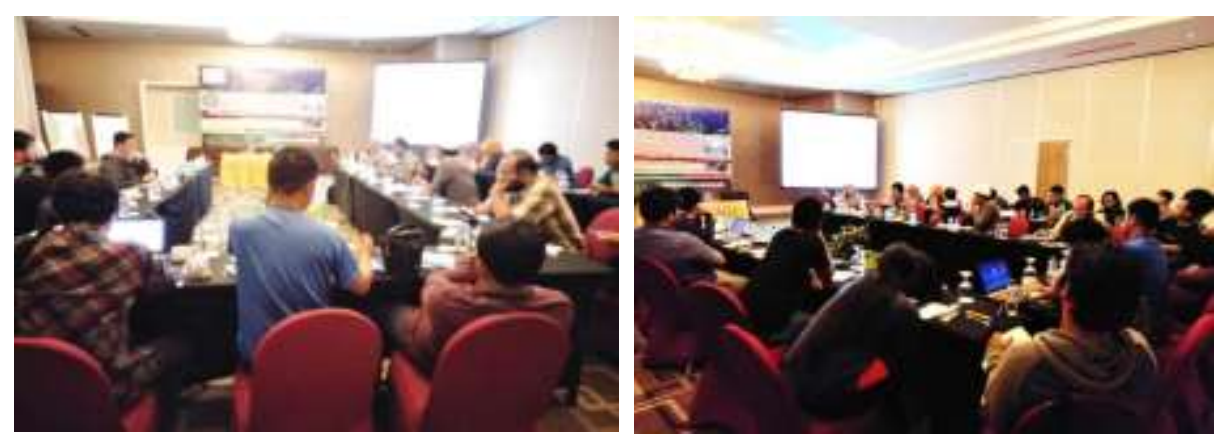

Gambar 2. Penyusunan Policy Brief oleh Koalisi Masyarakat Sipil 
Tahap ketiga, menyusun bersama policy brief yang berisi masukan terhadap rancangan peraturan daerah tentang rencana zonasi wilayah pesisir dan pulau-pulau kecil di Provinsi Kalimantan Timur. Substansi yang dihasilkan saat tahapan identifikasi masalah menjadi salah satu masukan isi dari policy brief.

Berikut rumusan hasil pembahasan partisipasi masyarakat dalam penyusunan RZWP3K Provinsi Kalimantan Timur yang disepakati dalam proses diskusi antar seluruh peserta:

\section{Masukan Kelompok Masyarakat Sipil \\ Dalam Penyusunan RZWP3K Provinsi Kalimantan Timur}

\section{A. Aspek Formil}

Tahapan Penyusunan RZWP3K Sesuai Permen kelautan dan perikanan Nomor 23 Tahun 2016 tentang perencanaan pengelolaan wilayah pesisir dan pulau-pulau kecil pasal 24, adalah Pengumpulan Data (Peta dasar dan Data tematik) yang dilakukan melalui data sekunder, jika belum memenuhi standar kualitas dan kuantitas yang dilengkapi dengan metadata, WAJIB melakukan pengumpulan data primer melalui survey lapangan.

B. Aspek Materiil

Aspek materil yang wajib diperhatikan berdasarkan ketentuan Pasal 17 ayat 2 Permen Kelautan dan Perikanan No. 13 Tahun 2016 adalah:

a. Alokasi Ruang untuk akses publik;

Perlu ada alokasi yang cukup bagi publik untuk mengakses pesisir dan laut, karena pada dasarnya kawasan pesisir merupakan kawasan publik (Common Proverty)

b. Alokasi Ruang untuk kepentingan nasional;

c. keserasian, keselarasan dan keseimbangan dengan RTRW provinsi dan RTRW kabupaten/ kota;

Perlu dipastikan bahwa kekhususan kecamatan pesisir WAJIB diatur dalam RZWP3K, TIDAK CUKUP diatur hanya dalam RTRW.

d. keterkaitan antara Ekosistem darat dan Ekosistem laut dalam satu bentang alam ekologis (bioekoregion);

e. kawasan, zona, dan/atau alur laut provinsi yang telah ditetapkan sesuai dengan peraturan perundangundangan;

f. Kajian Lingkungan Hidup Strategis;

Belum ada dokumen KLHS Kalimantan Timur

g. ruang penghidupan dan akses kepada nelayan kecil, nelayan tradisional, pembudidaya ikan kecil, dan petambak garam kecil;

- Perlu ada alokasi yang cukup bagi nelayan dan masyarakat yang menggantungkan hidupnya pada laut dan wilayah pesisir.

- Ketiadaan alokasi ruang yang cukup mengakibatkan konflik ruang antara masyarakat dengan 820ndustry.

h. wilayah Masyarakat Hukum Adat dan kearifan lokal;

- Perda RZWP3K tidak mengakomodir keberadaan masyarakat Adat disepanjang pesisir kalimantan timur padahal jelas sebaran masyarakat Adat disepanjang pesisir yang mengisi ruang-ruang hidup hampir disemua kabupaten.

i. peta risiko bencana

- Memastikan perlindungan terhadap kawasan ekosistem mangrove, terumbu karang, padang lamun, dan hutan konservasi.

Berdasarkan point-point diatas terlihat bahwa belum semua syarat dan tahapan terpenuhi dalam proses penyusunan RZWP3K Provinsi Kalimantan Timur. 
Seluruh tahapan kegiatan klinik hukum partisipasi masyarakat dalam penyusunan RZWP3K telah selesai dilakukan oleh Tim Klinik Hukum. Hasilnya bersama Koalisi Masyarakat Sipil Kalimantan Timur telah tersusun policy brief (Gambar. 3)(Prakarsa Borneo, 2019). sebagai bahan masukan kepada pemerintah dalam penyusunan dokumen RZWP3K Provinsi Kalimantan Timur. Hal ini sesuai sebagaimana tujuan akhir dari pelaksanaan klinik hukum.

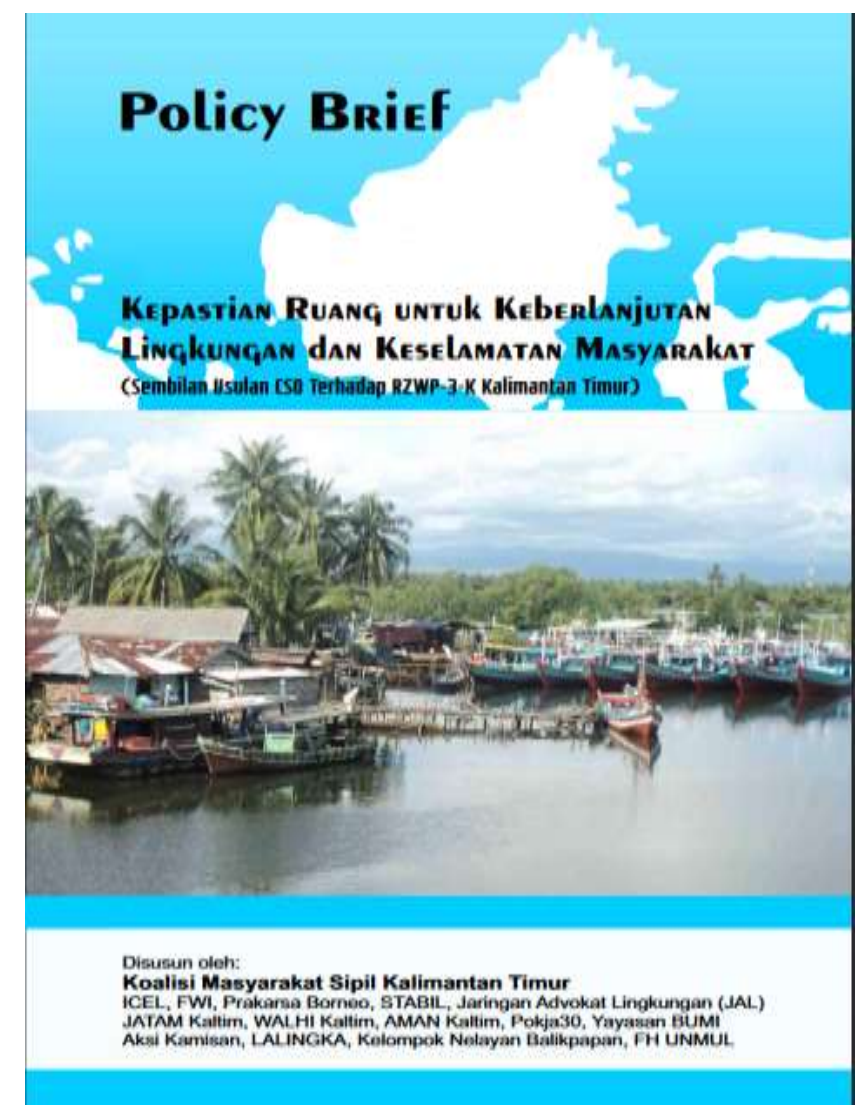

Gambar 3 : Policy Brief RZWP3K Kalimantan Timur

\section{KESIMPULAN}

Proses peningkatan pemahaman hukum mengenai hak masyarakat dalam penyusunan peraturan daerah dalam hal ini adalah rencana zonasi wilayah pesisir dan pulau-pulau kecil (RZWP3K) telah berhasil mendorong seluruh peserta terlibat aktif dalam proses identifikasi masalah yang dialami masyarakat pesisir teluk Balikpapan. Serta secara aktif Tim Klinik Hukum dan Koalisi Masyarakat Sipil menyusun Policy Brief dan menyampaikannya kepada pengambil kebijakan terkait penyusunan Raperda RZWP3K.

\section{UCAPAN TERIMA KASIH}

Terima kasih disampaikan kepada Pimpinan Fakultas Hukum Universitas Mulawarman yang memberikan pendanaan pelaksanaan kegiatan Klinik Hukum RZWP3K, serta Koalisi Masyarakat Sipil Kalimantan Timur dan Forum Nelayan Balikpapan yang telah bekerjasama dengan Pusat Studi Hukum Sumber Daya Alam (PSH-SDA) Fakultas Hukum Universitas Mulawarman.

\section{DAFTAR PUSTAKA}


Arumanto. (2018). Lembaga Lingkungan minta rencana zonasi Kaltim dihentikan. Antaranews.Com. https://kaltim.antaranews.com/berita/47885/lembaga-lingkungan-mintarencana-zonasi-kaltim-dihentikan

Azis, A. A. (2018). Kemelut Penyusunan Perda Rencana Tata Ruang Laut. Kaltimkece.Id. https://kaltimkece.id/warta/lingkungan/kemelut-penyusunan-perda-rencana-tata-ruanglaut

BPSD Pesisir dan Laut Padang. (2019). Rencana Zonasi Wilayah Pesisir dan Pulau-Pulau Kecil. Kkp.Go.Id. https://kkp.go.id/djprl/bpsplpadang/page/263-tata-ruang-laut

Hidayah, R. Al. (2018). Telaah Akademik Rancangan Perda RZWP3K Provinsi Kalimantan Timur, Makalah FGD Yayasan Bumi 8 juli 2018.

Julheri. (2020). KKP: Luas Kawasan Konservasi Perairan Indonesia Mencapai 23,9 Juta Hektar. Sumeks.Co. https://sumeks.co/kkp-luas-kawasan-konservasi-perairan-indonesia-mencapai239-juta-hektar/

Kaltim, D. (2019). Keputusan DPRD Nomor 1 tahun 2019 tentang Perpanjangan Masa Kerja Pansus. In Rabit: Jurnal Teknologi dan Sistem Informasi Univrab (Vol. 1, Issue 1, p. 2019). https://jdihn.go.id/files/1003/2019KEPDPRD001.pdf

Kasworo, Y. (2017). Urgensi Penyusunan Pengaturan Rencana Zonasi Wilayah Pesisir Dan PulauPulau Kecil. RechtsVinding MEDIA PEMBINAAN HUKUM NASIONAL, 1-3. https://rechtsvinding.bphn.go.id/view/view_online.php?id=233

Kementerian Kelautan dan Perikanan. (2016). Kajian Hukum Kelautan dan Perikanan terkait Kewajiban Indonesia terhadap Ketentuan Internasional dalam Pemanfaatan SumberDayaHayati. https://kkp.go.id/an-component/media/upload-gambarpendukung/SOSEK/policy_brief/Rekomendasi Sosek_Kajian Hukum (secured).pdf

Kementerian Lingkungan Hidup. (n.d.). Konvensi Keanekaragaman Hayati.pdf. http://perpustakaan.menlhk.go.id/pustaka/images/docs/Konvensi Keanekaragaman Hayati.pdf

Koalisi Masyarakat Sipil Untuk Keadilan Pesisir dan Pulau-Pulau kecil. (2020). Eksistensi Ekologi dan Nasib Nelayan di pertanyakan. https://fwi.or.id/wpcontent/uploads/2020/11/newsletter_Pandemi_Rencana-Zonasi.pdf

Kurnia, M. P., Susmiyati, H. R., \& Hamzah, H. (2016). Model of Public Participation in Formation of Good Local Regulation in East Kalimantan Province Model of Public Participation in Formation of Good Local Regulation in East Kalimantan Province. JL Pol'y \& Globalization, 55(55), 222. https://heinonline.org/hol-cgi-

bin/get_pdf.cgi?handle=hein.journals/jawpglob55\&section=26

Pemprov Kaltim. (2018). Pemanfaatan Wilayah Pesisir dan pulau Kecil Wajib Berijin. Kaltimprov.Go.Id. https://kaltimprov.go.id/berita/pemanfaatan-wilayah-pesisir-dan-pulaukecil-wajib-berijin

Prakarsa Borneo. (2019). Policy Brief Policy Brief Kepastian Ruang untuk Keberlanjutan Lingkungan dan Keselamatan Masyarakat (Sembilan Usulan CSO Terhadap RZWP-3K Kalimantan Timur). In fwi.or.id (Vol. 1). https://fwi.or.id/wpcontent/uploads/2020/03/Policy_Brief_RZWP3K_2019-1.pdf

Pratama, O. (2020). Konservasi Perairan Sebagai Upaya menjaga Potensi Kelautan dan Perikanan Indonesia. Kkp.Go.Id. https://kkp.go.id/djprl/artikel/21045-konservasi-perairan-sebagaiupaya-menjaga-potensi-kelautan-dan-perikanan-indonesia

Prihatiningtyas, W. (2019). Pengelolaan Wilayah Laut Oleh Pemerintah Daerah Berdasarkan Prinsip-Prinsip Good Environmental Governance. Media Iuris, 2(2), 279. https://doi.org/10.20473/mi.v2i2.14744

Ramses, R., Ashari, E., \& Ramdani, R. (2018). Inovasi Minuman Dan Panganan Berbahan Baku Bidara Laut (Ximenia Americana) Dan Mangrove Dari Pesisir Kota Batam. Dinamisia : Jurnal Pengabdian Kepada Masyarakat, 2(2), 197-204. https://doi.org/10.31849/dinamisia.v2i2.2068 